\title{
The Distribution of Teichoic Acids and Sugar 1-Phosphate Polymers in Walls of Micrococci
}

\author{
By MARGARET D. PARTRIDGE, A. L. DAVISON AND \\ J. BADDILEY \\ Microbiological Chemistry Research Laboratory, School of Chemistry, \\ University of Newcastle upon Tyne, Newcastle upon Tyne, NEI $7 R U$
}

(Received Io May 1972)

\section{SUMMARY}

A survey has been made of the nature of phosphorylated wall polymers in a number of micrococci. Polymers found include typical glycerol and ribitol teichoic acids (polymers of glycerol phosphate or ribitol phosphate) having different sugar substituents, atypical teichoic acids in which the repeating unit comprises glycerol phosphate and $\mathrm{N}$-acetylglucosamine I-phosphate, and sugar I-phosphate polymers. Distinct chemogroups can be recognized based on the composition and structure of the wall polymers.

\section{INTRODUCTION}

Polysaccharides, typical teichoic acids (polymers of glycerol phosphate or ribitol phosphate), an atypical teichoic acid (polymer containing glycerol phosphate and sugar I-phosphate residues) and sugar I-phosphate polymers have been found in the walls of micrococci (Davison \& Baddiley, I963, I964; Baddiley, Brock, Davison \& Partridge, I968). The atypical teichoic acid that has been studied in detail is the one in which the repeating unit comprises both glycerol phosphate and $\mathrm{N}$-acetylglucosamine I-phosphate (Archibald, Baddiley \& Button, 1968a; Archibald, Baddiley, Heckels \& Heptinstall, 1971) in Micrococcus sp. 13, and the sugar I-phosphate polymers include a $\operatorname{poly}(\mathrm{N}$-acetylglucosamine I-phosphate) in $\mathrm{Micro}$ coccus sp. 2102 (Archibald, Baddiley, Button, Heptinstall \& Stafford, I968b) and a poly(glucosyl- $\mathrm{N}$-acetylgalactosamine I-phosphate) in Micrococcus sp. AI (Partridge, Davison \& Baddiley, I97I).

This paper describes further studies on the occurrence of teichoic acids and sugar 1-phosphate polymers in the walls of micrococci, and indicates clearly recognizable chemotypes which could facilitate the taxonomy of these bacteria.

\section{METHODS}

Cultures of organisms were obtained from the National Collection of Industrial Bacteria (NCIB), the National Collection of Type Cultures (NCTC), the Czechoslovak Collection of Micro-organisms (CCM) and the American Collection of Type Cultures (ATCC). Micrococcus sp. AI-A5 were isolated by one of us (A.L.D.). Organisms were grown in batch culture and walls prepared by methods described previously (Davison, 1968). Polymers were extracted from washed walls with $5 \%(\mathrm{w} / \mathrm{v})$ trichloroacetic acid at $4{ }^{\circ} \mathrm{C}$, and characterized by hydrolysis with acid and alkali followed by paper chromatography of products. All of these procedures were described previously (Baddiley et al. I968), as were quantitative methods for the determination of sugars, amino sugars and phosphates (Partridge et al. 197I). 


\section{RESULTS}

Micrococcus sp. A2, 8I65 and NCIB 9996 contain typical ribitol teichoic acids, i.e. substituted poly(ribitol phosphate), in which the carbohydrate substituent is $\mathrm{N}$-acetylglucosamine. The acid hydrolysis products were alanine, glucosamine or its $\mathrm{N}$-acetyl derivative, ribitol phosphates, anhydroribitol and inorganic phosphate. Hydrolysis in alkali followed by treatment with phosphatase gave ribitol and its glucosaminide. Apparently not all of the ribitol phosphate residues were substituted by the amino sugar, and this was confirmed by the ratio amino sugar/phosphate for the strains 9996 and 8I65, which were 0.85: I and 0.7I:I respectively. A trace of glucose was noted in acid hydrolysates of the material from strain A2, but it is not known whether this represents glucosyl residues in the teichoic acid.

The Micrococcus sp. A3, ATCC 8456, NCIB 9995, NCTC I630 and NCTC 7729 possess typical glycerol teichoic acids in their walls. Acid hydrolysis gave alanine, glycerol and its monoand diphosphates, inorganic phosphate and several sugars. The material from strain A3 contains glucosamine and was not degraded by alkali; thus all or nearly all of its glycerol residues are substituted by $N$-acetylglucosamine. The polymers from the other strains were degraded by alkali giving 2-glycosides of glycerol and other products expected from partly glycosylated polymers of glycerol phosphate. That from strain 8456 contains both $\mathrm{N}$-acetylglucosamine and rhamnose (amino sugar/rhamnose/phosphate, 0.3:0.I:I), and several incompletely characterized glycerol glycosides were obtained from it by hydrolysis with alkali. Although paper electrophoresis in pyridine acetate, $\mathrm{pH} 8.5$, gave no evidence for the presence of more than one polymer, it is not known whether both sugars occur in the same polymer chains. The teichoic acids from strains 9995, I630 and 7729 possess glucosyl substituents. The ratio glucose/phosphate for strain 1630 is $0.54: 1$, and for strain 7729 it is $0.64: \mathrm{I}$. As both polymers are completely degraded to products of low molecular weight in alkali the glycerol phosphate chains are partly glucosylated, and are not mixtures of fully glucosylated and unsubstituted molecules. The mild extraction procedures would not have caused the hydrolysis of glycosidic linkages. $N$-Acetylgalactosaminyl residues were detected in the material from strain 9995 .

Teichoic acids closely similar to or identical to that previously isolated from the walls of Micrococcus sp. 13 were obtained from strains A4, NCTC 4736 and NCTC 8340 . They possess a repeating unit in which glycerol is attached through a phosphodiester linkage to a hydroxyl group of $\mathrm{N}$-acetylglucosamine I-phosphate; the inter-unit linkage is between the phosphate at the I-position and the terminal hydroxyl of glycerol on a neighbouring unit (Archibald et al. 1968a). They contain $\mathrm{N}$-acetylglucosamine, glycerol and phosphate in the molecular proportions $\mathrm{I}: \mathrm{I}: 2$, and acid hydrolysis gave mainly alanine, glucosamine and glycerol diphosphates, together with small amounts of glycerol monophosphates and inorganic phosphate. Hydrolysis in alkali gave coloured products and glucometasaccharinic acid and its 6-phosphate. Partial acid hydrolysis yielded a monomeric product with the same analytical composition as the polymers (no alanine); it contained a phosphomonoester and a phosphodiester residue, was reducing and, after treatment with the phosphomonoesterase, gave one molar proportion of formaldehyde on oxidation with periodate. Thus these teichoic acids are probably structurally identical to that from strain 13; the exact location of the glycerol phosphate substituent on the sugar was not established.

Sugar I-phosphate polymers are present in the walls of Micrococcus sp. A5 and NCTC 963. The polymer from strain A5 contains only $N$-acetylglucosamine and phosphate in equimolar amounts. It is indistinguishable from the $N$-acetylglucosamine I-phosphate polymer previously isolated from the walls of strain $20 \mathrm{I} 2$ (Archibald et al. 1968b). On hydrolysis in 
Table I. Strains of Micrococcaceae

Classification

Micrococcus candicans Micrococcus luteus

Micrococcus sp.

Staphylococcus lactis
Origin, etc.

Baird-Parker grouping

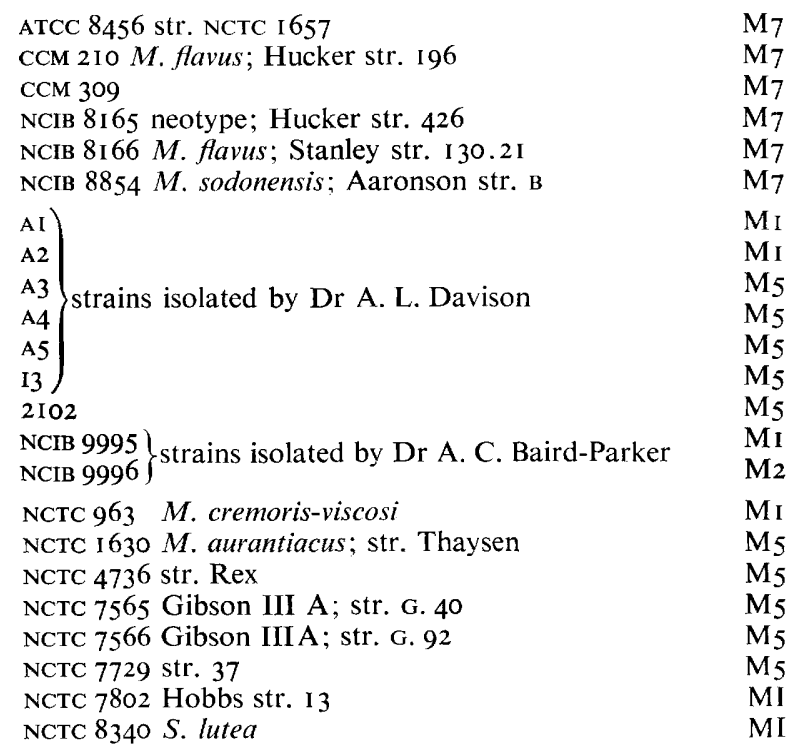

Table 2. Teichoic acids and sugar I-phosphate polymers in walls of micrococci

$\begin{array}{lll}\text { Micrococcus sp. } & \text { Phosphorylated polymer in wall } & \text { Substituents } \\ \text { A2 } & \text { Ribitol teichoic acid } & N \text {-Acetylglucosamine } \\ \text { NCIB } 8 \text { I } 65 & \text { Ribitol teichoic acid } & N \text {-Acetylglucosamine } \\ \text { NCIB } 9996 & \text { Ribitol teichoic acid } & N \text {-Acetylglucosamine } \\ \text { A3 } & \text { Glycerol teichoic acid } & N \text {-Acetylglucosamine } \\ \text { ATCC } 8456 & \text { Glycerol teichoic acid } & N \text {-Acetylglucosamine, rhamnose } \\ \text { NCIB } 9995 & \text { Glycerol teichoic acid } & \text { Glucose, } N \text {-acetylgalactosamine } \\ \text { NCTC I630 } & \text { Glycerol teichoic acid } & \text { Glucose } \\ \text { NCTC 7729 } & \text { Glycerol teichoic acid } & \text { Glucose } \\ \text { I3 } & \text { Glycerol teichoic acid (atypical) } & N \text {-Acetylglucosamine } \\ \text { A4 } & \text { Glycerol teichoic acid (atypical) } & N \text {-Acetylglucosamine } \\ \text { NCTC } 4736 & \text { Glycerol teichoic acid (atypical) } & N \text {-Acetylglucosamine } \\ \text { NCTC } 8340 & \text { Glycerol teichoic acid (atypical) } & N \text {-Acetylglucosamine } \\ \text { A5 } & \text { Poly }(N \text {-acetylglucosamine I-phosphate) } \\ 2 \text { 102 } & \text { Poly } N \text {-acetylglucosamine I-phosphate) } \\ \text { A I } & \text { Poly(glucosyl- } N \text {-acetylgalactosamine I-phosphate) } \\ \text { NCTC } 963 & \text { Glucose- } N \text {-acetylgalactosamine I-phosphate polymer }\end{array}$

alkali a brown colour was produced together with a phosphate of glucometasaccharinic acid; this phosphate gave glucometasaccharinic acid on incubation with the phosphatase. On controlled acid hydrolysis ( $0.1 \mathrm{M}-\mathrm{HCl}$ at $100{ }^{\circ} \mathrm{C}$ for $30 \mathrm{~min}$ ) it gave in high yield a monophosphate of $\mathrm{N}$-acetylglucosamine. The polymer reduced I molecular proportion of

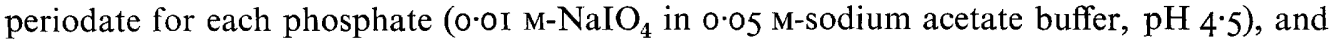
reduction of the product with sodium borohydride followed by acid hydrolysis (Smith degradation, see Archibald et al. 1968a) gave glycerol phosphate. As for the polymer from strain 2102, the phosphodiester linkage is between the I-position and the 6-position of an adjacent unit. 
The structure of the polymer in the walls of strain AI has been established by chemical and enzymatic studies as a poly[ $\alpha$-D-glucopyranosyl-(I $\rightarrow 3)$ - $N$-acetyl-D-galactosamine I-phosphate] in which the phosphate linkage is to the 6-position on glucose in adjacent units (Partridge et al. I97I). The polymer from strain NCTC 963 is similar, but the molecular proportions glucose/ $N$-acetylgalactosamine/phosphate are I:2:I, suggesting that it might comprise a trisaccharide I-phosphate repeating unit.

Neither teichoic acids nor sugar I-phosphate polymers were found in certain Micrococcus sp., which were not investigated further: Micrococcus luteus CCM $2 \mathrm{IO}$ and 309, NCIB 8I 66 and 8854 , Micrococcus sp. NCTC 7565,7566 and 7802 . The occurrence of polymers in walls of the organisms examined is summarized in Table 2.

\section{DISCUSSION}

Distinct chemogroups of wall polymers are apparent in micrococci. Ribitol and glycerol teichoic acids, now recognized as common components of cell walls of micro-organisms (Archibald \& Baddiley, 1966; Baddiley, 1970), have been found in strains of micrococci included in this survey; these polymers resemble those found in previous investigations (Davison \& Baddiley, 1963; Baddiley et al. 1968).

Glucosaminylribitol teichoic acid is a component of walls of Micrococcus luteus NCIB 8I 65 , but not of other $M$. luteus strains studied. This strain, for which a low ratio guanine:cystosine has been reported (Rosypal, Rosypalová \& Hořejš, 1966), is clearly anomalous and on the basis of cell wall analysis should not be designated as neotype. Glucosaminylribitol teichoic acids in micrococci differ from those in strains of Staphylococcus aureus. In the former glycosylation is incomplete, whereas in all wild strains of $S$. aureus each ribitol unit is substituted with one $N$-acetylglucosamine (Baddiley, Buchanan, RajBhandary \& Sanderson, 1962; Davison \& Baddiley, 1963). Similarly the glucosylglycerol teichoic acids in the walls of halotolerant micrococci differ from the fully glycosylated representatives in strains of Staphylococcus epidermidis of clinical origin (Davison \& Baddiley, 1964).

Polymers containing $N$-acetylglucosamine I-phosphate residues, found in several physiologically related acetoin-negative micrococci, are either atypical teichoic acids in which glycerol phosphate and $N$-acetylglucosamine I-phosphate occur in combination in the repeating unit (Archibald et al. I968a), or they are simple polymers of $N$-acetylglucosamine I-phosphate (Archibald et al. 1968 b). These cocci, all members of Baird-Parker's subgroup 5 (Baird-Parker, 1965), constitute a chemogroup characterized by the presence in their walls of polymers containing $N$-acetylglucosamine I-phosphate and are distinct from others in subgroup 5 which contain conventional wall teichoic acids or polysaccharides (Baddiley et al. 1968).

Two strains of acetoin-positive micrococci possess sugar I-phosphate polymers containing galactosamine in their walls. The polymer in strain NCTC 963 contains two galactosamine residues to one glucose and, although its structure is not known, it clearly differs from the polymer in species AI in which the repeating unit is a disaccharide phosphate, glucosyl- $N$ acetylgalactosamine I-phosphate (Partridge et al. 197I). These cocci represent a further chemogroup, and appear to be less halotolerant than are those strains possessing teichoic acids. Strain NCTC 963 (Micrococcus cremoris-viscosi) studied by Abd-el-Malek \& Gibson (I948), occupies an intermediate position within their Staphylococcus-Micrococcus system. A very closely related disaccharide I-phosphate polymer, probably differing only in the configuration of the glucosyl linkage, has been found in Bacillus subtilis Marburg strain I68 (V. A. Shibaev, unpublished observation). 
The base composition of the DNA in strains AI, A5 and 13 discussed in this study has not been determined accurately, but preliminary measurements indicate that it is within the accepted range for micrococci. The establishment of chemogroups and characteristic strains based on the composition of wall polymers should be of value in the consideration of overall systems of classification for the genus which would take into account physiology, base composition, immunology and chemical structure.

We thank the Science Research Council for a studentship (to M.D.P.).

\section{REFERENCES}

ABd-eL-Malek, Y. \& Gibson, T. (1948). Studies in the bacteriology of milk. II. The staphylococci and micrococci in milk. Journal of Dairy Research $\mathbf{1 5}, 249-260$.

ARchibald, A. R. \& Baddiley, J. (1966). The teichoic acids. Advances in Carbohydrate Chemistry 21, 323375 .

Archibald, A. R., Baddilfy, J. \& Button, D. (I $968 a$ ). The glycerol teichoic acid of walls of Staphylococcus lactis I3. Biochemical Journal I10, 543-556.

Archibald, A. R., Baddiley, J., Button, D., Heptinstall, S. \& Stafford, G. H. (ig68b). Occurrence of polymers containing $N$-acetylglucosamine I-phosphate in bacterial walls. Nature, London 219, 855-856.

Archibald, A. R., Baddiley, J., Heckels, J. E. \& Heptinstall, S. (1971). Further studies on the glycerol teichoic acid of walls of Staphylococcus lactis I3. Location of the phosphodiester groups and their susceptibility to hydrolysis with alkali. Biochemical Journal r25, 353-359.

BADDILEY, J. (1970). Structure, biosynthesis and function of teichoic acids. Accounts of Chemical Research, 3, 98-105.

Baddiley, J., Buchanan, J. G., RajBhandary, U. L. \& Sanderson, A. R. (1962). Teichoic acid from walls of Staphylococcus aureus H. Biochemical Journal 82, 439-448.

Baddiley, J., Brock, J. H., Davison, A. L. \& Partridge, N. D. (I968). The wall composition of micrococci. Journal of General Microbiology 54, 393-396.

BAIRD-PARKeR, A. C. (1965). The classification of staphylococci and micrococci from world-wide sources. Journal of General Microbiology 38, 363-387.

DAVISON, A. L. (1968). The characterization of a Micrococcus (Staphylococcus lactis) sp. I 3 with an atypical teichoic acid in its wall. Biochemical Journal nıo, 557-558.

Davison, A. L. \& BADDILEY, J. (I963). The distribution of teichoic acids in staphylococci. Journal of General Microbiology 32, 27I-276.

DAvison. A. L. \& BADDILEY, J. (1964). Glycerol teichoic acids in walls of Staphylococcus epidermidis. Nature, London 202, 874.

Partridge, M. D., Davison, A. L. \& Baddiley, J. (1971). A polymer of glucose and $N$-acetylgalactosamine I-phosphate in the wall of Micrococcus sp. AI. Biochemical Journal r21, 695-700.

Rosypal, S., Rosypaloví, A. \& HoŘejš, J. (1966). The classification of micrococci and staphylococci based on their DNA base composition and Adansonian analysis. Journal of General Microbiology 44, 28I-292. 